\title{
KLF5 promotes the tumorigenesis and metastatic potential of thyroid cancer cells through the $\mathrm{NF}-\kappa \mathrm{B}$ signaling pathway
}

\author{
YUEHUA MA $^{1,2}$, QINGZHU WANG $^{1}$, FEI LIU $^{1}$, XIAOJUN MA ${ }^{1}$, LINA WU $^{1}$, \\ FENG GUO $^{1}$, SHUIYING ZHAO ${ }^{1}$, FENGJUAN HUANG ${ }^{1}$ and GUIJUN QIN ${ }^{1,3}$ \\ ${ }^{1}$ Department of Endocrinology, The First Affiliated Hospital of Zhengzhou University, Zhengzhou, Henan 450052; \\ ${ }^{2}$ Department of Endocrinology, Henan Provincial People's Hospital and the People's Hospital \\ of Zhengzhou University, Zhengzhou, Henan 450003; ${ }^{3}$ Institute of Clinical Medicine, \\ The First Affiliated Hospital of Zhengzhou University, Zhengzhou, Henan 450052, P.R. China
}

Received February 22, 2018; Accepted September 3, 2018

DOI: 10.3892/or.2018.6687

\begin{abstract}
The purpose of the present study was to identify the potential function of Kruppel-like factor 5 (KLF5) in thyroid cancer and investigate the underlying mechanisms. The protein levels of KLF5 in 98 thyroid cancer tissues were analyzed using an immunohistochemistry assay. SW579 cells transfected with small interfering RNA against KLF5 and B-CPAP cells transfected with KLF5 expressing vectors were used for functional studies. Western blot analysis, immunofluorescence and co-immunoprecipitation assays were used to investigate the mechanisms of KLF5. In vivo tumorigenicity was assessed using a subcutaneous xenograft experiment. The results revealed that KLF5 was highly expressed in thyroid cancer tissues and associated with lymph node metastasis. Knockdown of KLF5 in SW579 cells suppressed proliferation, anchorage-independent growth, migration and invasion in vitro, while the overexpression of KLF5 resulted in opposite effects in B-CPAP cells. Mechanistically, it was demonstrated that KLF5 promoted the cytoplasm-nuclear translocation of nuclear factor- $\kappa \mathrm{B}$. Additionally, it was revealed that insufficient F-box/WD repeat-containing protein 7 expression may be responsible for the dysfunction of KLF5 in thyroid cancer. These results revealed that KLF5 promotes the tumorigenesis and metastasis of thyroid cancer cells and may be a potential therapeutic target in patients with thyroid cancer.
\end{abstract}

\section{Introduction}

Thyroid cancer is a common endocrine malignancy with continuously increasing incidence in the past decade (1).

Correspondence to: Dr Guijun Qin, Department of Endocrinology, The First Affiliated Hospital of Zhengzhou University, 1 Jian She Dong Avenue, Zhengzhou, Henan 450052, P.R. China

E-mail: hyqingj@zzu.edu.cn

Key words: Kruppel-like factor 5, thyroid cancer, tumorigenesis, metastasis, nuclear factor- $\mathrm{\kappa} \mathrm{B}$
Globally in 2012, there were estimated to be $\sim 230,000$ novel cases of thyroid cancer among women and 70,000 among men (2). Thyroid cancer may be divided into parafollicular C cell-derived medullary thyroid cancer (MTC) and follicular epithelial cell-derived tumor types, including papillary thyroid cancer (PTC), follicular thyroid cancer (FTC), anaplastic thyroid cancer (ATC) and poorly differentiated thyroid cancer (PDTC). These subtypes of thyroid cancer exhibit different phenotypes, clinical behaviors and molecular mechanisms (3). The constitutive activity of the RET proto-oncogene is a well-reported mechanism for MTC (4), while the molecular pathogenesis of follicular epithelial cell-derived thyroid cancer includes genetic and epigenetic alterations, including mutation, gene copy-number gain, aberrant gene expression and post-translational modification $(3,5)$. Investigating these molecular alterations may provide novel insight into potential treatment strategies for this cancer type.

Kruppel-like factor 5 (KLF5) is a critical member of the KLF family (6). The KLF5 gene is located at chromosome $13 \mathrm{q} 21$, which was frequently deleted in human cancer types $(7,8)$. KLF5 protein contains a proline rich transactivation domain and three zinc-finger domains $(9,10)$. A number of studies have demonstrated the association between KLF5 and human malignancies. Du et al (11) reported that KLF5 promoted cell migration and increased the lamellipodia formation of bladder cancer. In hepatocellular carcinoma, KLF5 was upregulated in CD44C/CD133C cells and was essential for the regulation of cancer stem cells (12). However, evidence in prostate cancer demonstrated that KLF5 loss promoted tumor angiogenesis through inhibiting phosphoinositide 3-kinase $(\mathrm{PI} 3 \mathrm{~K}) /$ protein kinase B (AKT) signaling (13). Thus, the biological function of KLF5 remains controversial and may be tumor-type dependent.

The involvement of KLF5 in thyroid cancer remains largely unknown. The present study aimed to clarify the biological roles and mechanisms of KLF5 in thyroid cancer.

\section{Materials and methods}

Clinical data. The Ethics Committee of Zhengzhou University (Zhengzhou, China) ethically approved the study protocol, and 
written informed consent was obtained from each participant prior to enrollment in the study. Between January 2015 and December 2016, 98 paired thyroid cancer tissues (24 males and 74 females; age range, 23-54 years; median age, 37 years) were collected from The First Affiliated Hospital of Zhengzhou University. Patients, who received preoperative treatment including radiation or chemotherapy, or had tumor types of other organs, were excluded from the cohort used in the present study. All cases were clinically and histologically diagnosed.

Immunohistochemistry (IHC) assay. The samples were fixed with $4 \%$ buffered formaldehyde for $48 \mathrm{~h}$ at room temperature and embedded in paraffin. Then a tissue microarray containing 98 paired thyroid cancer tissues and adjacent non-cancerous tissues were constructed. For the IHC assay, the sections (4 $\mu \mathrm{m})$ were deparaffinized, rehydrated and heated in citric buffer at $100^{\circ} \mathrm{C}$ for antigen retrieval. Endogenous peroxidase activity was inactivated by adding $3 \%$ hydrogen peroxide for $5 \mathrm{~min}$ at room temperature. Then the sections were incubated with anti-KLF5 (1:200; cat. no. 21017-1-AP; ProteinTech Group, Inc., Chicago, IL, USA) at $4^{\circ} \mathrm{C}$ overnight. The next day, sections were washed three times with PBS, incubated with goat anti-rabbit immunoglobulin $\mathrm{G}$ ( $\mathrm{IgG}$ ) second antibodies (dilution 1:1,000; cat. no. ab6720; Abcam, Cambridge, MA, USA) at $37^{\circ} \mathrm{C}$ for $30 \mathrm{~min}$ and visualized using the Metal Enhanced DAB Substrate kit (Thermo Fisher Scientific, Inc., Waltham, MA, USA) according to the manufacturer's protocol. Finally, the sections were counterstained with hematoxylin ( $0.5 \%$ for $1 \mathrm{~min}$ at room temperature) and dehydrated with graded concentrations of ethanol (70\% ethanol for $2 \mathrm{~min}, 95 \%$ ethanol for $2 \mathrm{~min}$ and absolute ethanol for $2 \mathrm{~min}$ ) and dimethyl benzene.

Scoring was performed by two investigators of The First Affiliated Hospital of Zhengzhou University (Dr Qingzhu Wang and Dr Fei Liu) independently, and discrepancies were resolved by consensus with another researcher (Dr Lina $\mathrm{Wu}$ ). The proportion of positive cells was scored as $0(<10 \%), 1(10-25 \%), 2(26-50 \%)$ or 3 (>50\%); staining intensity was scored as 0 (no staining), 1 (weak staining), 2 (moderate staining) or 3 (strong staining). The final score of each case was determined by multiplying the proportion and intensity scores. For statistical analysis, cases were divided into KLF5 low expression (0-3) or high expression (4-9) groups.

Cell culture. Human thyroid cancer cell lines SW579 and B-CPAP were obtained from the Type Culture Collection of the Chinese Academy of Sciences (Shanghai, China). B-CPAP was originally classified as a PTC cell line but is now considered to be a PDTC cell line (14). SW579 was a squamous cell carcinoma cell line of human thyroid cancer. Cells were cultured in Dulbecco's modified Eagle's medium (DMEM; Hyclone; GE Healthcare Life Sciences, Logan, UT, USA) supplemented with $10 \%$ fetal bovine serum (FBS; Hyclone; GE Healthcare Life Sciences) in a humidified incubator at $37^{\circ} \mathrm{C}$ with $5 \% \mathrm{CO} 2$.

Transient transfection. Small interfering RNAs (siRNAs) targeting KLF5 and the scrambled (scrRNA) siRNAs were synthesized by Shanghai GenePharma Co., Ltd. (Shanghai, China). KLF5 or F-box/WD repeat-containing protein 7
(FBW7) expressing plasmids and the empty vector were obtained from Shanghai GeneChem Co., Ltd. (Shanghai, China). For transient transfection, $3 \times 10^{5}$ SW579/B-CPAP cells were plated into 6 -well plates until they reached $70 \%$ confluence. Then cells were transfected $\left(48 \mathrm{~h}\right.$ at $37^{\circ} \mathrm{C}$ ) with $8 \mu \mathrm{l} \mathrm{siRNA} / 4$ $\mu \mathrm{g}$ DNA and $10 \mu \mathrm{l}$ Lipofectamine 2000 (Invitrogen; Thermo Fisher Scientific, Inc.) according to the manufacturer's protocol. RNA/protein extraction and all the functional studies were conducted $48 \mathrm{~h}$ after transfection. The siRNA target sequences were: siRNA\#1, 5'-CGAUUACCCUGGUUGCACA-3'; siRNA\#2, 5'-AAGCUCACCUGAGGACUCA-3'. To stably silence KLF5, pLVshRNA-EGFP(2A)Puro vectors (Cyagen US Inc., Santa Clara, CA, USA) expressing short hairpin RNA (shRNA/sh) negative control (shNC), shKLF5\#1 (target sequence: 5'-CGATTACCCTGGTTGCACA-3') or shKLF5\#2 (target sequence: 5'-AAGCTCACCTGAGGACTCA-3') were established. Then, $3 \times 10^{5} \mathrm{SW} 579$ cells were seeded in to a 6-well plate and transient transfection $\left(48 \mathrm{~h}\right.$ at $\left.37^{\circ} \mathrm{C}\right)$ was performed using Lipofectamine 2000 when the cells reached $70 \%$ confluence. Stable cells were selected with culture medium containing puromycin $(5 \mu \mathrm{g} / \mathrm{ml}$; Beyotime Institute of Biotechnology, Haimen, China). Stable B-CPAP/NC and B-CPAP/KLF5 colonies were obtained by G418 selection ( $400 \mu \mathrm{g} / \mathrm{ml}$ for 10 days; Beyotime Institute of Biotechnology) following transient transfection. The knockdown/overexpression efficacy of KLF5 was verified using a western blot assay.

RNA extraction and reverse transcription-quantitative polymerase chain reaction ( $R T-q P C R)$. Total RNA of the clinical samples was isolated with TRIzol reagent (Invitrogen; Thermo Fisher Scientific, Inc.) and cDNA was synthesized using a RT kit (Promega Corporation, Madison, WI, USA) according to the manufacturer's protocol. qPCR was conducted using an Applied Biosystems 7900 System and the SYBR Green Reagent kit (Applied Biosystems; Thermo Fisher Scientific, Inc.) to quantitatively determine the mRNA levels of KLF5 according to the manufacturer's protocol. The PCR primers used in the present study were as follows: GAPDH forward, 5'-GGTGAAGGTCGGAGTCAACG-3' and reverse, 5'-TGGGTGGAATCATATTGGAACA-3'; KLF5 forward, 5'-ACACCAGACCGCAGCTCCA-3' and reverse, 5'-TCCATTGCTGCTGTCTGATTTGTAG-3'. The thermocycling conditions were as follows: Precubation at $95^{\circ} \mathrm{C}$ for $10 \mathrm{~min}$; amplification at $95^{\circ} \mathrm{C}$ for $10 \mathrm{sec}, 60^{\circ} \mathrm{C}$ for $10 \mathrm{sec}$ and $72^{\circ} \mathrm{C}$ for $10 \mathrm{sec}$ for 45 cycles; melting at $95^{\circ} \mathrm{C}$ for $10 \mathrm{sec}, 65^{\circ} \mathrm{C}$ for $60 \mathrm{sec}$ and $97^{\circ} \mathrm{C}$ for $1 \mathrm{sec}$. The fold amplification for gene expression was determined using the $2^{-\Delta \Delta \mathrm{Cq}}$ method (15).

Western blotting. SW579/B-CPAP cells were lysed (30 min at $4^{\circ} \mathrm{C}$ ) with RIPA buffer (Beijing Solarbio Science \& Technology Co., Ltd., Beijing, China) in the presence of a protease inhibitor cocktail (Sigma Aldrich; Merck KGaA, Darmstadt, Germany) and phosphatase inhibitor Cocktail III (Cell Signaling Technology, Inc., Danvers, MA, USA). Protein concentrations were determined using a BCA Protein Assay kit (Pierce; Thermo Fisher Scientific, Inc.). The proteins (20 $\mu \mathrm{g}$ per lane) were resolved using 10\% sodium dodecyl sulfate-polyacrylamide gel electrophoresis (SDS-PAGE) and then transferred to polyvinylidene fluoride membranes (EMD Millipore, Billerica, MA, USA). The membranes were blocked 
with $5 \%$ bovine serum albumin ( $1 \mathrm{~h}$ at room temperature) and incubated with the corresponding primary antibodies including KLF5 rabbit polyclonal antibody (dilution 1:1,000; cat. no. 21017-1-AP; ProteinTech Group., Inc.), FBW7 mouse monoclonal antibody (dilution 1:1,000; cat. no. ab74054; Abcam), nuclear matrix protein $\mathrm{p} 84$ mouse monoclonal antibody (dilution 1:1,000; cat. no. ab487; Abcam), fibronectin rabbit polyclonal antibody (dilution 1:1,000; cat. no. ab2413; Abcam), E-Cadherin rabbit $\mathrm{mAb}$ (dilution 1:1,000; cat. no. 3195; Cell Signaling Technology, Inc.), Vimentin rabbit mAb (dilution 1:1,000; cat. no. 5741; Cell Signaling Technology, Inc.), Twist family BHLH transcription factor 1 (Twist1) rabbit mAb (dilution 1:1,000; cat. no. 46702; Cell Signaling Technology, Inc.), IкB $\alpha$ Mouse mAb (dilution 1:1,000; cat. no. 4814; Cell Signaling Technology, Inc.), phosphorylated (p)-IкB $\alpha$ rabbit mAb (dilution 1:1,000; cat. no. 2859; Cell Signaling Technology, Inc.), inhibitor of nuclear factor NF- $\mathrm{\kappa B}$ subunit $\beta$ (IKK $\beta$ ) rabbit $\mathrm{mAb}$ (dilution 1:1,000; cat. no. 8943; Cell Signaling Technology, Inc.), p-IKK $\beta$ rabbit mAb (dilution 1:1,000; cat. no. 2697; Cell Signaling Technology, Inc.), NF-кB p65 rabbit $\mathrm{mAb}$ (dilution 1:1,000; cat. no. 8242; Cell Signaling Technology, Inc.), p44/42 extracellular signal-regulated kinase 1 and 2 (Erk1/2) rabbit mAb (dilution 1:1,000; cat. no. 4695; Cell Signaling Technology, Inc.), p-p44/42 Erk1/2 rabbit mAb (dilution 1:1,000; cat. no. 4370; Cell Signaling Technology, Inc.), AKT rabbit mAb (dilution 1:1,000; cat. no. 4685; Cell Signaling Technology, Inc.), p-AKT rabbit mAb (dilution 1:1,000; cat. no. 4060; Cell Signaling Technology, Inc.) and GAPDH mouse monoclonal antibody (dilution 1:5,000; cat. no. 60004-1-Ig; ProteinTech Group., Inc.) at $4^{\circ} \mathrm{C}$ overnight. The membranes were washed with tris-buffered saline with Tween-20 (0.1\%) at room temperature (three times for $10 \mathrm{~min}$ ), and then incubated with horseradish peroxidase (HRP)-conjugated goat anti-rabbit IgG (dilution 1:5,000; cat. no. SA00001-2; ProteinTech Group., Inc.) or HRP-conjugated goat anti-mouse $\operatorname{IgG}$ secondary antibodies (dilution 1:5,000; cat. no. SA00001-1; ProteinTech Group., Inc.). Finally, the protein bands were visualized and quantified by using the electrochemiluminesence reagent (Thermo Fisher Scientific, Inc.) and Tanon 5200 Multi Fully Automatic Chemiluminescence/ Fluorescence Image Analysis System which includes a Gel Image system software (version 4.2.5; Tanon Science and Technology Co., Ltd., Shanghai, China).

Co-immunoprecipitation (Co-IP). For the Co-IP assay, lysates of SW579 cells were incubated with a protein A/G agarose (Beyotime Institute of Biotechnology) at $4^{\circ} \mathrm{C}$ for $1 \mathrm{~h}$ to remove non-specific hybrid proteins. Whole cell lysates obtained by centrifugation $\left(12,000 \mathrm{x} \mathrm{g}\right.$ at $4^{\circ} \mathrm{C}$ for $\left.5 \mathrm{~min}\right)$ were incubated with $2 \mu \mathrm{g}$ KLF5 rabbit polyclonal antibody (dilution 1:200; cat. no. 21017-1-AP; ProteinTech Group., Inc.) or the control rabbit IgG (dilution 1:200; cat. no. A7016; Beyotime Institute of Biotechnology), FBW7 mouse monoclonal antibody (dilution 1:200; cat. no. ab74054; Abcam) or the control mouse IgG (dilution 1:200; cat. no. A7028; Beyotime Institute of Biotechnology) at $4^{\circ} \mathrm{C}$ overnight. Then the samples were incubated with protein $\mathrm{A} / \mathrm{G}$ agarose (Beyotime Institute of Biotechnology) for $4 \mathrm{~h}$ at $4^{\circ} \mathrm{C}$ to capture the antigen-antibody complex. Following centrifugation at $12,000 \times \mathrm{x}$ at $4^{\circ} \mathrm{C}$ for $5 \mathrm{sec}$, the supernatants were removed. Then, the agarose bead-antigen-antibody complex was washed 3 times with pre-cooled PBS. The bound proteins were boiled in SDS sample buffer and resolved by $10 \%$ SDS-PAGE for a western blotting assay.

Cell proliferation assay. A Cell Counting Kit-8 (CCK-8; Dojindo Molecular Technologies, Inc., Kumamoto, Japan) assay was used to assess the cell proliferation ability. A total of 1,000 cells were plated and adhered onto 96 well plates and optical density values at $450 \mathrm{~nm}$ were measured subsequent to adding CCK-8 (incubation for $2 \mathrm{~h}$ at $37^{\circ} \mathrm{C}$ ) on day $1,2,3,4,5$ and 6 . B-CPAP/KLF5 cells were cultured with medium containing NF- $\kappa B$ inhibitor SC75741 $(5 \mu \mathrm{M}$; Selleck Chemicals, Houston, TX, USA) or vehicle [dimethyl sulfoxide (DMSO; Sangon Biotech Co., Ltd., Shanghai, China)] for 1, 2, $3,4,5$ and 6 days (at $37^{\circ} \mathrm{C}$ ) to evaluate the influence of NF- $\mathrm{kB}$ on cell proliferation.

Anchorage-independent growth assay in soft agar. For the anchorage-independent growth assay, low-melting point agarose was soluted in diluted water at concentrations of 1.2 and $0.6 \%$. The agarose solutions were then incubated in a thermostat water bath at $40^{\circ} \mathrm{C}$ for $12 \mathrm{~h}$ following autoclaving. Agarose (1.2\%) and 2X DMEM medium (with 20\% FBS) were mixed at a ratio of $1: 1$, and $3 \mathrm{ml}$ of the mixture was injected into a 6-well plate. Then $0.6 \%$ agarose $(1.5 \mathrm{ml})$ and $2 \mathrm{X}$ DMEM medium containing $2 \times 10^{4}$ cells $(1.5 \mathrm{ml})$ were mixed at a ratio of $1: 1$, and the mixture was injected into the upper layer once the basal layer dried. Colonies were photographed and counted 2-3 weeks later. Upper agar containing NF-кB inhibitor SC75741 (5 $\mu \mathrm{M}$; Selleck Chemicals) or vehicle (DMSO) was used to evaluate the influence of NF- $\mathrm{KB}$ on anchorage-independent growth.

Transwell assay. Cell migration and Matrigel invasion assays were performed using Transwell inserts (Corning Life Science). SW579/B-CPAP cells $\left(1 \times 10^{5}\right)$ in $200 \mu 1$ serum-free DMEM were placed in the upper chamber and the lower compartments were filled with $600 \mu \mathrm{l}$ DMEM containing 10\% FBS. After $48 \mathrm{~h}$ culturing at $37^{\circ} \mathrm{C}$, tumor cells in the upper side of chamber were removed with cotton swabs and tumor cells in the lower chamber were stained with $0.5 \%$ crystal violet for $30 \mathrm{~min}$ at room temperature. Migrated cells were photographed under an Olympus inverted microscope (Olympus Corporation, Tokyo, Japan) for counting. To evaluate the influence of NF- $\kappa B$ on cell migration/invasion, B-CPAP/KLF5 cells were plated into the upper chamber of the Transwell and complete medium containing NF- $\kappa \mathrm{B}$ inhibitor (SC75741, $5 \mu \mathrm{M}$ ) or vehicle (DMSO) were added into the lower compartments.

Immunofluorescence (IF). A total of 1x104 SW579/B-CPAP cells were seeded onto slides, fixed with $4 \%$ paraformaldehyde at room temperature for $10 \mathrm{~min}$, permeabilized with 0.5\% NP-40 (Sigma-Aldrich; Merck KGaA) and blocked with $10 \%$ normal goat serum (Beijing Solarbio Science \& Technology Co., Ltd.) for $20 \mathrm{~min}$ at room temperature. Then the slides were incubated with NF- $\mathrm{kB}$ p65 Rabbit monoclonal antibody (mAb; dilution 1:400; cat. no. 8242; Cell Signaling Technology, Inc.) at $4^{\circ} \mathrm{C}$ overnight. Subsequent to three washes using PBS for $5 \mathrm{~min}$, the slides were incubated with Alexa Fluor ${ }^{\circledR} 555$ Conjugate secondary antibody (dilution 1:200; 
cat. no. 4413; Cell Signaling Technology, Inc.) for $1 \mathrm{~h}$ at $37^{\circ} \mathrm{C}$. Finally, the slides were incubated with DAPI (dilution 1:1,000; cat. no. C1002; Beyotime Institute of Biotechnology) for $10 \mathrm{~min}$ at $37^{\circ} \mathrm{C}$. For the cytoskeleton assay, the slides were incubated with Alexa Fluor 568 dye-conjugated phalloidin (dilution, 1:1,000; cat. no. A12380; Invitrogen; Thermo Fisher Scientific, Inc.) for $2 \mathrm{~h}$ at $37^{\circ} \mathrm{C}$ and DAPI (dilution 1:1,000; cat. no. C1002; Beyotime Institute of Biotechnology) for $10 \mathrm{~min}$ at $37^{\circ} \mathrm{C}$. Images were obtained using a fluorescent microscopy (Olympus Corporation).

Protein stability assay. A cycloheximide (CHX) assay was used to determine the half-life of KLF5. SW579 cells were transfected with an empty vector or FBW7 expressing plasmid. $\mathrm{CHX}$ was added to the cell culture (at $37^{\circ} \mathrm{C}$ ) at a concentration of $0.1 \mathrm{mg} / \mathrm{ml}$ and cells were harvested at $0.0,0.5,1.0$ and $2.0 \mathrm{~h}$. Then, cell lysates were analyzed using western blotting.

In vivo experiments. All experiments were performed strictly in accordance with a protocol ethically approved by the Institutional Animal Care and Use Committee of Zhengzhou University. A number of 15 male BALB/c nude mice (4-weeks-old) were obtained from Beijing Vital River Laboratory Animal Technology Co., Ltd. (Beijing, China). The mice were maintained under a $12 \mathrm{~h}$ dark/light cycle with ad libitum access to food in specific pathogen-free conditions (55\% humidity and $22^{\circ} \mathrm{C}$ ). SW579/shNC, SW579/shKLF5\#1 and SW579/shKLF5\#2 cells ( $1 \times 10^{6}$ in $\left.100 \mu \mathrm{lPBS}\right)$ were subcutaneously injected into the right flank of nude mice $(5$ mice per group). Tumor sizes were measured every 10 days using vernier calipers and the final volume was calculated using the following formula: $\mathrm{V}=$ length $\mathrm{x}$ width ${ }^{2} / 2$. Mice were sacrificed at the 40th day using cervical dislocation euthanasia. The subcutaneous xenografts were weighed, fixed with $4 \%$ buffered formaldehyde for $48 \mathrm{~h}$ at room temperature and embedded in paraffin for IHC assays. To evaluate the effects of KLF5 on metastatic potential, B-CPAP/NC or B-CPAP/KLF5 cells were intravenously injected $\left(3 \times 10^{6}\right.$ in $\left.100 \mu \mathrm{PBS}\right)$ into the tail vein of nude mice ( 5 mice per group). On day 40 , the mice were sacrificed using cervical dislocation. Lungs were carefully dissected out of the chest and washed with PBS. Then the metastatic nodules on the lung surface were counted. Then the lungs of each group were stained with hematoxylin $(0.5 \%)$ and eosin $(0.05 \%)$ for pathological confirmation. The sections $(4 \mu \mathrm{m})$ were deparaffinized, rehydrated, stained with hematoxylin for $5 \mathrm{~min}$ at room temperature and then stained with eosin staining solution for $3 \mathrm{~min}$ at room temperature. Pictures were taken using an Olympus inverted microscope (Olympus Corporation).

Statistical analysis. Statistical analysis was performed with SPSS 18.0 (SPSS Inc., Chicago, IL, USA). All data were presented as the mean \pm standard deviation. Differences were analyzed with unpaired Student's t-test between two groups or with one-way analysis of variance (followed by a Bonferroni post hoc test) among three groups. The association between KLF5 expression and the clinicopathological parameters of patients with thyroid cancer were analyzed using $\chi^{2}$ or Fisher's exact tests. A Spearman's rank correlation test was used to evaluate the correlation between KLF5 expression and FBW7
Table I. Association of KLF5 expression with clinicopathological parameters in patients with thyroid cancer.

\begin{tabular}{|c|c|c|c|c|}
\hline \multirow[b]{2}{*}{ Variable } & \multirow{2}{*}{$\begin{array}{l}\text { Cases } \\
\text { (n) }\end{array}$} & \multicolumn{2}{|c|}{$\begin{array}{c}\text { KLF5 } \\
\text { expression }\end{array}$} & \multirow[b]{2}{*}{ P-value } \\
\hline & & Low & High & \\
\hline Age (years) & & & & 0.645 \\
\hline$<45$ & 63 & 24 & 39 & \\
\hline$\geq 45$ & 35 & 15 & 20 & \\
\hline Sex & & & & 0.240 \\
\hline Male & 24 & 12 & 12 & \\
\hline Female & 74 & 27 & 47 & \\
\hline Tumor size (cm) & & & & 0.078 \\
\hline$<2$ & 70 & 24 & 46 & \\
\hline$\geq 2$ & 28 & 15 & 13 & \\
\hline Lymph node metastasis & & & & 0.027 \\
\hline Yes & 30 & 7 & 23 & \\
\hline No & 68 & 32 & 36 & \\
\hline Tumor types & & & & 0.931 \\
\hline Papillary & 66 & 26 & 40 & \\
\hline Follicular & 27 & 11 & 16 & \\
\hline Anaplastic & 5 & 2 & 3 & \\
\hline
\end{tabular}

KLF5, Kruppel-like factor 5.

expression. $\mathrm{P}<0.05$ was considered to indicate a statistically significant difference.

\section{Results}

Expression of KLF5 in benign and malignant thyroid lesions. KLF5 expression in thyroid cancer was determined using an IHC assay. It was revealed that the protein levels of KLF5 were significantly upregulated in thyroid cancer tissues, particularly in lymph node metastatic cases, compared with non-tumor tissues [non-tumor vs. thyroid cancer ( $\mathrm{LN}-), \mathrm{P}=0.039$; nontumor vs. thyroid cancer $\left(\mathrm{LN}^{+}\right), \mathrm{P}<0.001$; Fig. $1 \mathrm{~A}$ and $\left.\mathrm{B}\right]$. The detailed association between KLF5 expression and the clinicopathological parameters of patients with thyroid cancer is presented in Table I. KLF5 expression was revealed to be associated with lymph node metastasis using a $\chi^{2}$ test $(\mathrm{P}=0.027)$. However, no significant differences were observed between KLF5 expression and other variables, including age, sex, tumor size and tumor type.

KLF5 promotes the proliferation and anchorage-independent growth of thyroid cancer cells. The thyroid cancer cell line SW579 demonstrated higher levels of KLF5 compared with B-CPAP cells (Fig. 2A). The knockdown efficacy of KLF5 in SW579 cells and overexpression efficacy of KLF5 in B-CPAP cells were verified using a western blot assay (Fig. 2A). The result of a CCK-8 assay revealed that the siRNAs significantly inhibited the proliferation ability of SW579 cells compared with the scrambled control (siRNA\#1, $\mathrm{P}=0.002$; siRNA\#2, $\mathrm{P}<0.001$; Fig. 2B, upper panel), while the overexpression 
A

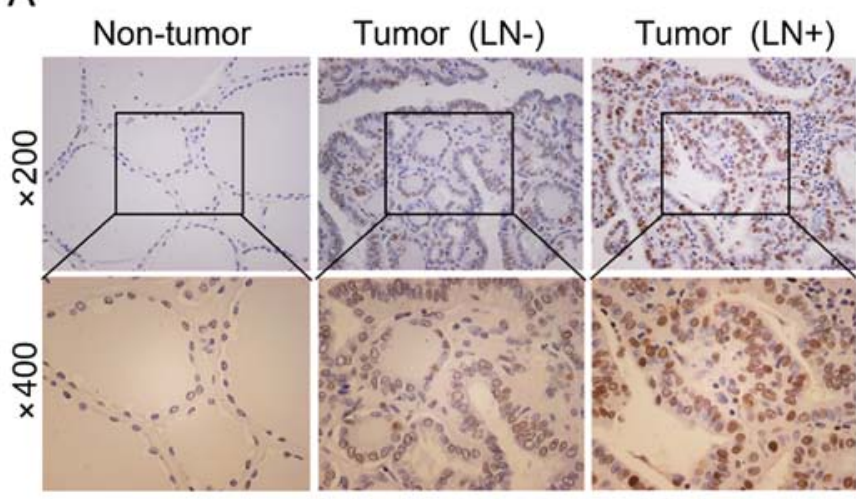

B

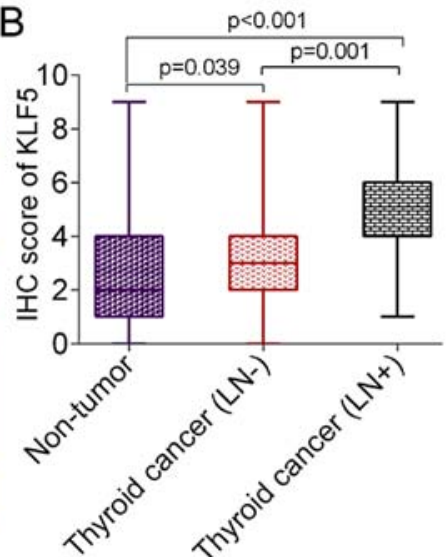

Figure 1. Evaluation of KLF5 expression in benign and malignant thyroid lesions. (A) Representative IHC images of KLF5 in non-tumor tissues, thyroid cancer tissues without LN metastasis and thyroid cancer tissues with LN metastasis. (B) Statistical analysis of KLF5 scores in non-tumor tissues, thyroid cancer tissues without LN metastasis and thyroid cancer tissues with LN metastasis. KLF5, Kruppel-like factor 5; LN, lymph node; IHC, immunohistochemistry.
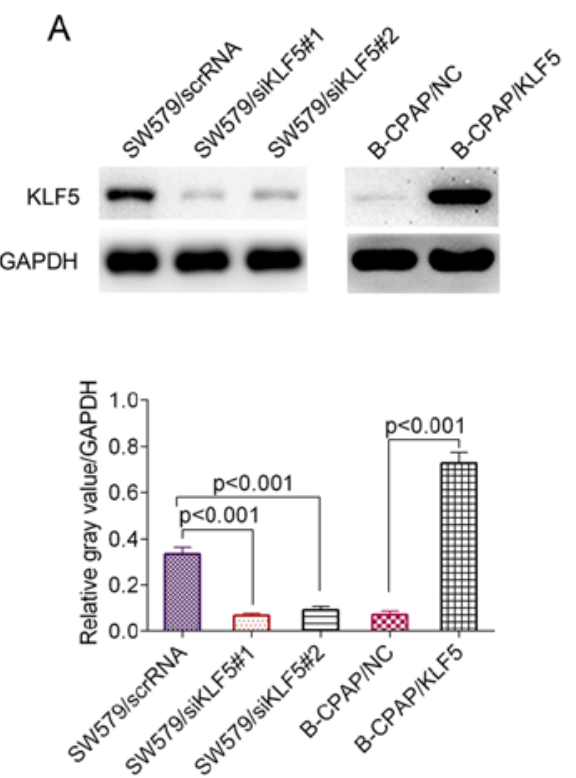

B
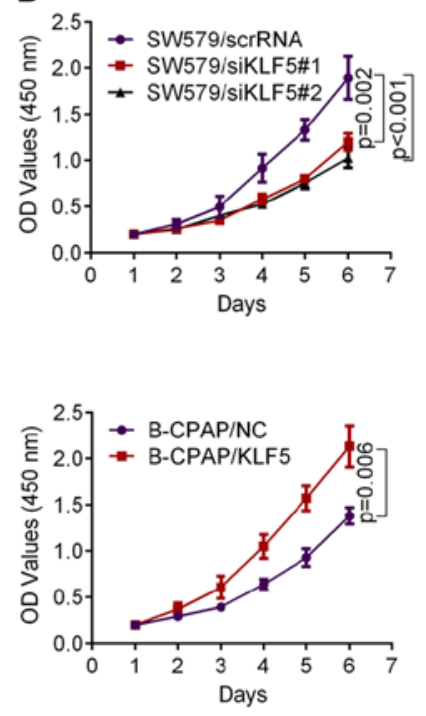

C
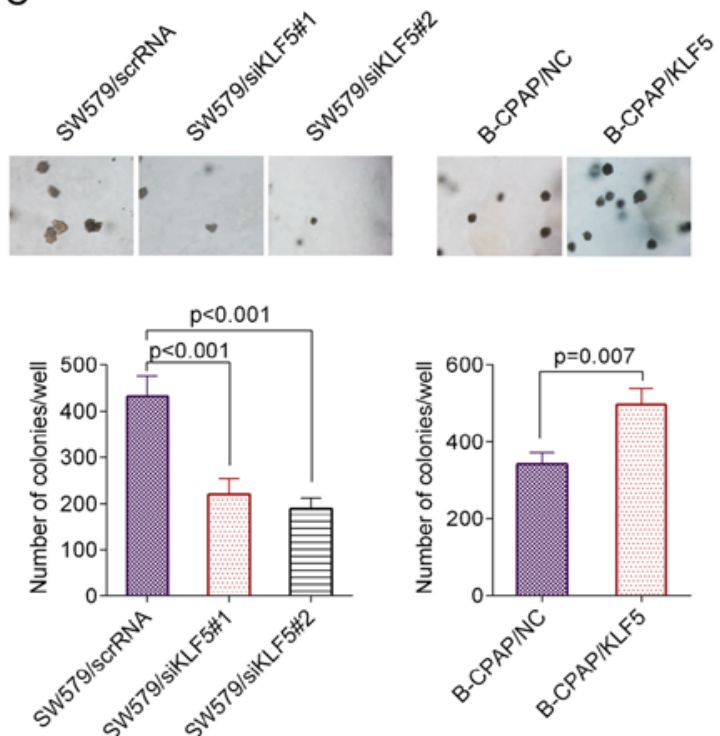

Figure 2. Effect of KLF5 on cell growth in vitro. (A) Knockdown and overexpression efficacy of KLF5 verified by western blot analysis. (B) Cell proliferation of SW579/scrRNA, SW579/siKLF5\#1 and SW579/siKLF5\#2 cells was evaluated using a CCK-8 assay (upper panel); Cell proliferation of B-CPAP/NC and B-CPAP/KLF5 cells was determined using a CCK-8 assay (lower panel). (C) Anchorage-independent growth assay in SW579 and B-CPAP cells. Knockdown of KLF5 inhibited the anchorage-independent growth of SW579 cells while the overexpression of KLF5 promoted the anchorage-independent growth of B-CPAP cells. KLF5, Kruppel-like factor 5; scrRNA, scrambled RNA; si-, small interfering RNA; NC, negative control; OD, optical density; CCK-8, Cell Counting Kit-8.

of KLF5 significantly promoted the proliferation ability of B-CPAP cells compared with the scrambled control $(\mathrm{P}=0.006$; Fig. 2B, lower panel). In the anchorage-independent growth assay, SW579/scrRNA cells induced a significantly greater number of single-cell-derived colonies compared with the SW579/siRNA\#1 cells or SW579/siRNA\#2 cells (siRNA\#1, $\mathrm{P}<0.001$; siRNA\#2, $\mathrm{P}<0.001$; Fig. $2 \mathrm{C}$, left panel), while the overexpression of KLF5 significantly promoted the anchorageindependent growth of B-CPAP cells compared with the negative control (NC; $\mathrm{P}=0.007$; Fig. 2C, right panel).

KLF5 promotes the metastatic potential of thyroid cancer cells. The present study further assessed cell migration and invasion ability using a Transwell assay. As presented in Fig. 3A, the knockdown of KLF5 by the two siRNAs significantly inhibited the migration and invasion ability of SW579 cells compared with the scrambled control (migration: SW579/scrRNA vs. SW579/ siRNA\#1, P<0.001; SW579/scrRNA vs. SW579/siRNA\#2, $\mathrm{P}<0.001$; invasion: SW579/scrRNA vs. SW579/siRNA\#1, $\mathrm{P}=0.001$; SW579/scrRNA vs. SW579/siRNA\#2, $\mathrm{P}=0.001)$. In accordance with these results, the knockdown of KLF5 significantly decreased the levels of a number of metastasis-associated markers, including fibronectin $(\mathrm{P}<0.01)$, Twist1 $(\mathrm{P}<0.001)$ and vimentin $(\mathrm{P}<0.01)$, while it significantly promoted the level of metastasis suppressor molecule E-cadherin $(\mathrm{P}<0.05$; Fig. $3 \mathrm{C}$ and D). Similar results were obtained from IF staining. SW579/ siRNA\#1 or SW579/siRNA\#2 cells revealed an increased number of actin stress fibers compared with SW579/scrRNA 
A
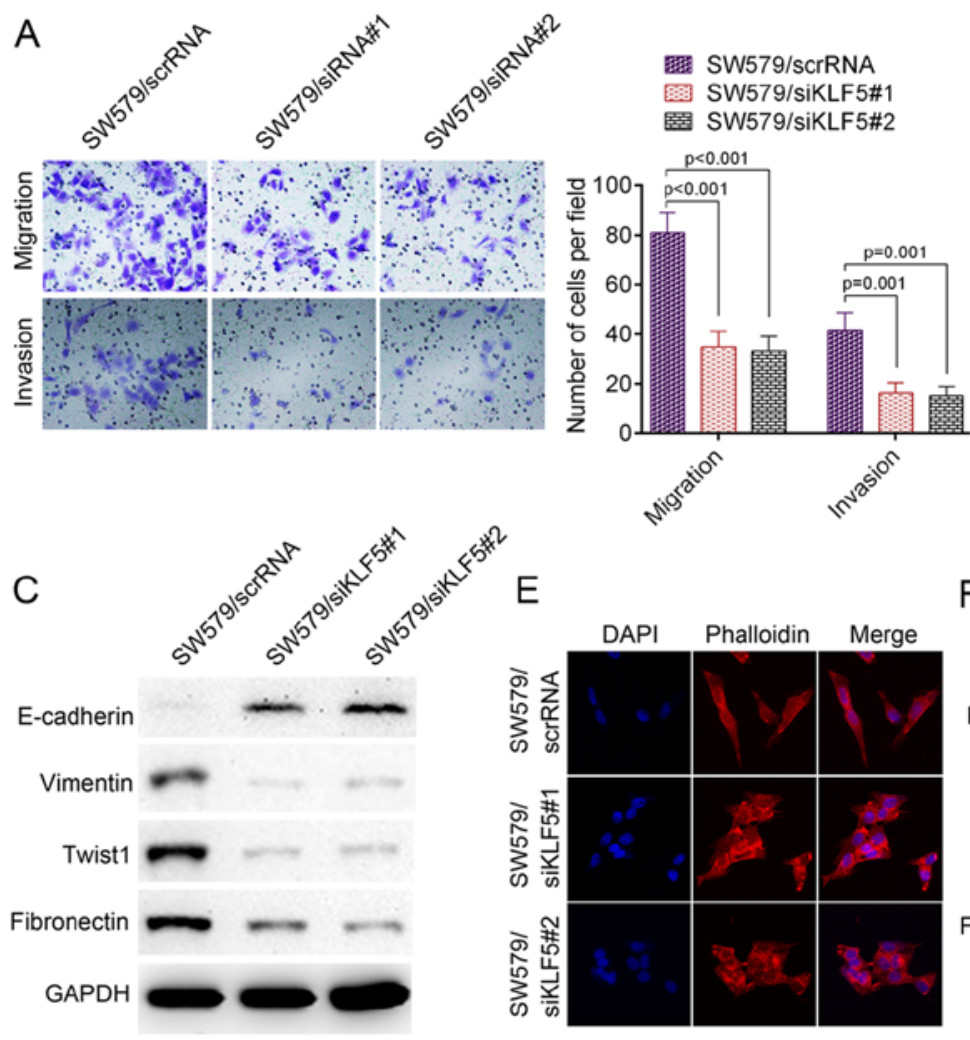

D
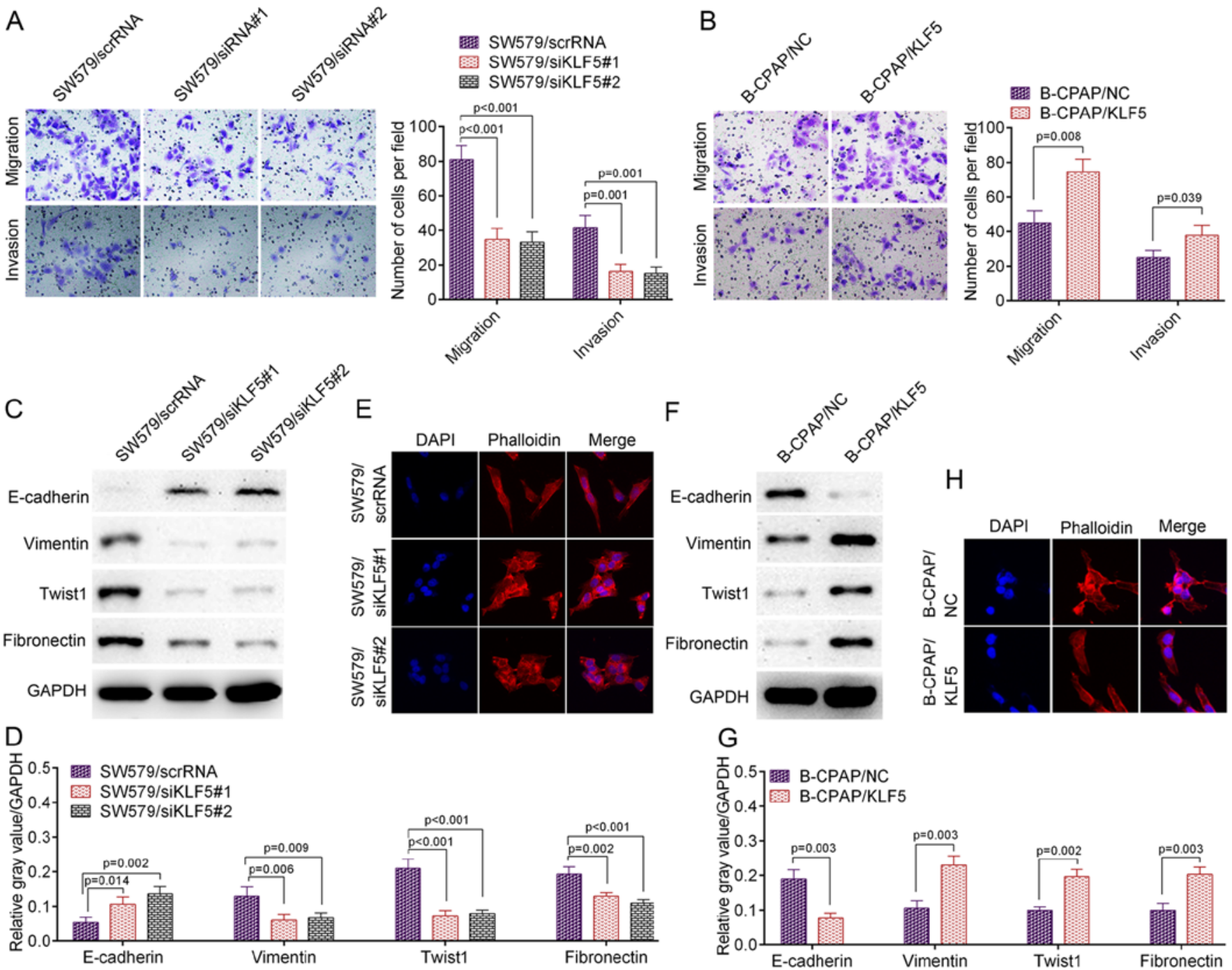

G

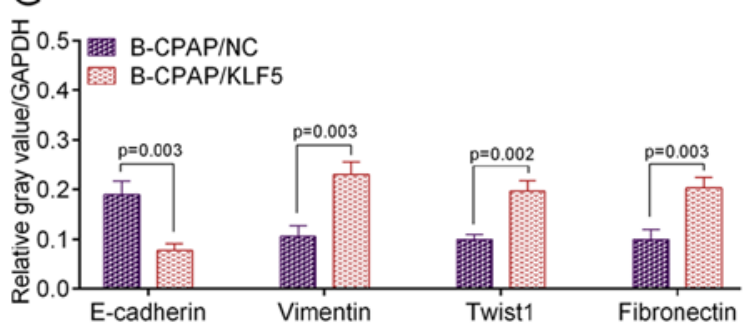

Figure 3. KLF5 promoted the invasive and metastatic potential of thyroid cancer cells in vitro. (A) Cell migration/invasion of SW579/scrRNA, SW579/ siKLF5\#1 and SW579/siKLF5\#2 was analyzed using a Transwell assay. (B) Cell migration/invasion of B-CPAP/NC and B-CPAP/KLF5 cells was assessed using a Transwell assay. (C) Western blot analysis of lysates from SW579/scrRNA, SW579/siKLF5\#1 and SW579/siKLF5\#2 cells using anti-E-cadherin, antivimentin, anti-Twist1 and anti-fibronectin and (D) the western blot analysis results quantified. (E) Immunostaining of phalloidin (F-actin) in SW579/scrRNA, SW579/siKLF5\#1 and SW579/siKLF5\#2 cells. (F) Western blot analysis of lysates from B-CPAP/NC and B-CPAP/KLF5 cells using the indicated antibodies and $(\mathrm{G})$ the western blot analysis results quantified. (H) Immunostaining of phalloidin (F-actin) in B-CPAP/NC and B-CPAP/KLF5 cells. KLF5, Kruppel-like factor 5; scrRNA, scrambled RNA; si-, small interfering RNA; NC, negative control; Twist1, Twist family BHLH transcription factor 1.

cells, which indicated decreased motility (Fig. 3E). The opposite result was observed in B-CPAP/KLF5 cells, which demonstrated an increased migration and invasion ability compared with $\mathrm{B}-\mathrm{CPAP} / \mathrm{NC}$ cells (migration, $\mathrm{P}=0.008$; invasion, $\mathrm{P}=0.039$; Fig. 3B). In addition, B-CPAP/KLF5 cells demonstrated significantly higher levels of fibronectin $(P<0.01)$, Twist1 $(P<0.01)$ and vimentin $(P<0.01)$, significantly lower levels of E-cadherin $(\mathrm{P}<0.01$; Fig. $3 \mathrm{~F}$ and $\mathrm{G})$ and fewer actin stress fibers (Fig. 3H) compared with B-CPAP/NC cells. Collectively, these data indicated that KLF5 promoted the metastatic potential of thyroid cancer cells.

KLF5 activates the NF- $\kappa B$ signalling pathway in thyroid cancer cells. The downstream mechanisms of KLF5 are complicated and the reported signaling pathways involved include the extracellular-regulated kinase (ERK) pathway, AKT pathway and the NF- $\kappa$ B pathway in addition to their crosstalk $(13,16-18)$. In thyroid cancer cells, KLF5 demonstrated no significant influence on the activation of EKR or AKT signaling pathways (Fig. 4). However, the NF- $\kappa B$ pathway may be activated by KLF5 in the two cell lines used in the present study. As presented in Fig. 5A and B, the knockdown of KLF5 in SW579 cells significantly decreased the protein level of $\mathrm{p}-\mathrm{I} \kappa \mathrm{B}-\alpha(\mathrm{P}<0.001)$, $\mathrm{p}-\mathrm{IKK}-\beta(\mathrm{P}=0.006)$ and nuclear NF- $\kappa B$ p65 $(\mathrm{P}=0.001)$. It was additionally observed that the overexpression of KLF5 in B-CPAP cells significantly promoted the levels of $p-I \kappa B-\alpha(P=0.011), p-I K K-\beta(P=0.005)$ and nuclear NF- $\mathrm{B}$ p65 $(\mathrm{P}<0.001)$. Notably, the IF assay for NF-kB p65 in SW579 cells revealed that the knockdown of KLF5 substantially decreased nuclear NF- $\mathrm{KB}$ p65, while the overexpression of KLF5 in B-CPAP cells promoted nuclear NF- $\mathrm{B}$ p65 (Fig. 5C). In summary, KLF5 promoted NF- $\kappa \mathrm{B}$ cytoplasmic-nuclear translocation in thyroid cancer cells.

Blocking the NF- $\kappa B$ signalling pathway abolishes KLF5induced phenotypes. To investigate the contribution of NF- $\mathrm{KB}$ 


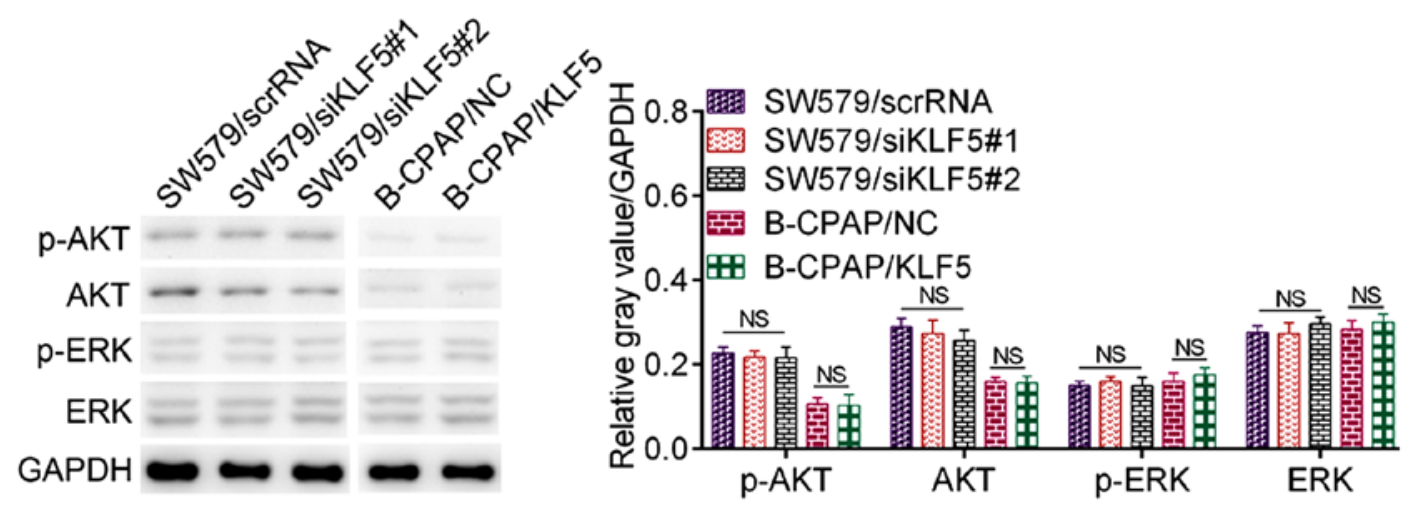

Figure 4. Effect of KLF5 on the ERK pathway and the AKT pathway. Western blot analysis of p-ERK, ERK, p-AKT and AKT in SW579 cells (SW579/scrRNA, SW579/siKLF5\#1 and SW579/siKLF5\#2) and B-CPAP cells (B-CPAP/NC and B-CPAP/KLF5). KLF5, Kruppel-like factor 5; scrRNA, scrambled RNA; si-, small interfering RNA; NC, negative control; AKT, protein kinase B; p-, phosphorylated; ERK, extracellular-regulated kinase; NS, not significant.
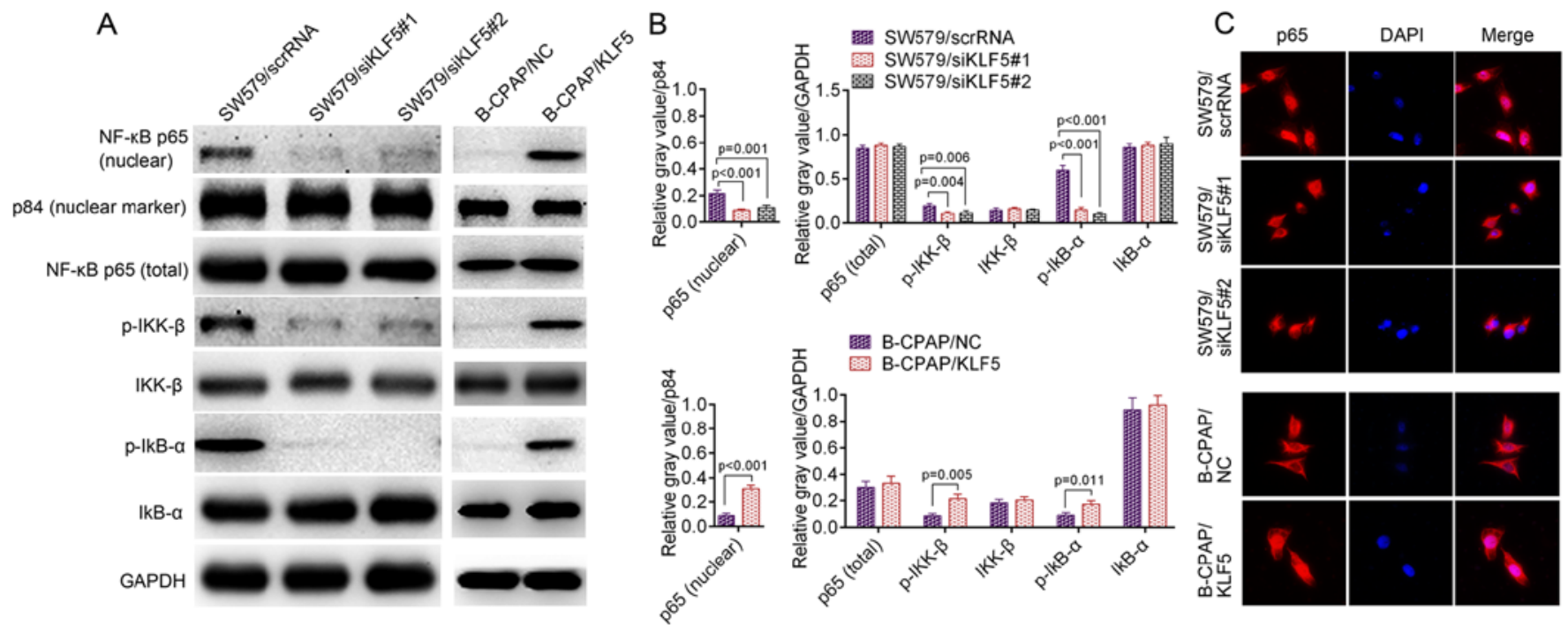

Figure 5. (A) Western blotting of p-IкB- $\alpha$, p-IKK- $\beta$ and nuclear NF-кB p65 in SW579 cells (SW579/scrRNA, SW579/siKLF5\#1 and SW579/siKLF5\#2, left panel) and B-CPAP cells (B-CPAP/NC and B-CPAP/KLF5, right panel); and p84 was used as a nuclear marker. (B) Quantified western blotting results.

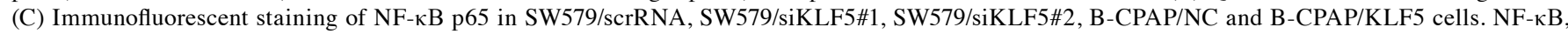
nuclear factor- $\kappa \mathrm{B}$; p-, phosphorylated-; IKK- $\beta$, inhibitor of nuclear factor $\kappa \mathrm{B}$ kinase subunit $\beta$; IкB- $\alpha$, nuclear factor of $\kappa$ light polypeptide gene enhancer in B-cells inhibitor, $\alpha$; scrRNA, scrambled RNA; si, small interfering RNA; NC, negative control; KLF5, Kruppel-like factor 5.

activation to KLF5-induced phenotypes, B-CPAP/KLF5 cells were treated with the specific NF-KB inhibitor SC75741. Subsequent to incubation with SC75741, B-CPAP/KLF5 cells exhibited significantly decreased nuclear NF- $\mathrm{kB}$ p65 $(\mathrm{P}<0.001$; Fig. 6A and B). Furthermore, the proliferation $(\mathrm{P}<0.001$; Fig. 6C), colony formation $(\mathrm{P}<0.001$; Fig. 6D), migration $(\mathrm{P}<0.001)$ and invasion $(\mathrm{P}=0.001$; Fig. $6 \mathrm{E})$ ability of $\mathrm{B}-\mathrm{CPAP} /$ KLF5+SC75741 cells was significantly reduced compared with the B-CPAP/KLF5+DMSO group. These data suggest that KLF5 regulates the aggressive phenotypes of thyroid cancer cells through activating the NF- $\mathrm{kB}$ signaling pathway.

$F B W 7$ is responsible for the ubiquitination and degradation of KLF5. Although the IHC assay revealed significantly higher protein levels of KLF5 in thyroid cancer tissues compared with normal tissues $(\mathrm{P}<0.001)$, the results of RT-qPCR revealed no significant differences in KLF5 mRNA levels between thyroid cancer tissues and non-tumor tissues $(n=98, P>0.05$; data not shown). This result suggested that KLF5 may be regulated by post-translational mechanisms. A previous study revealed that KLF5 is an unstable protein, which may be regulated by the E3 ubiquitin ligase FBW7 (19). Thus, the present study examined the interaction between FBW7 and KLF5 by a Co-IP assay in SW579 cells (Fig. 7A). It was observed that FBW7 reduced the KLF5 half-life compared with the control group and that the effect may be blocked by the proteasome inhibitor MG132 (Fig. 7B and C). These results suggest that FBW7 is an upstream regulator for KLF5 and may be responsible for the dysregulation of KLF5 in thyroid cancer cells.

KLF5 expression levels negatively correlate with $F B W 7$ in tumor tissues. Given that KLF5 was a direct target of FBW7 for degradation in thyroid cancer cells, the correlation between KLF5 and FBW7 in tumor tissues was further evaluated. As presented in Fig. 8A, representative tissue sections revealed that the protein levels of KLF5 and FBW7 were negatively correlated in thyroid cancer tissues and the results were summarized in Fig. 8B $(r=-0.435, P<0.001)$. Collectively, these results 

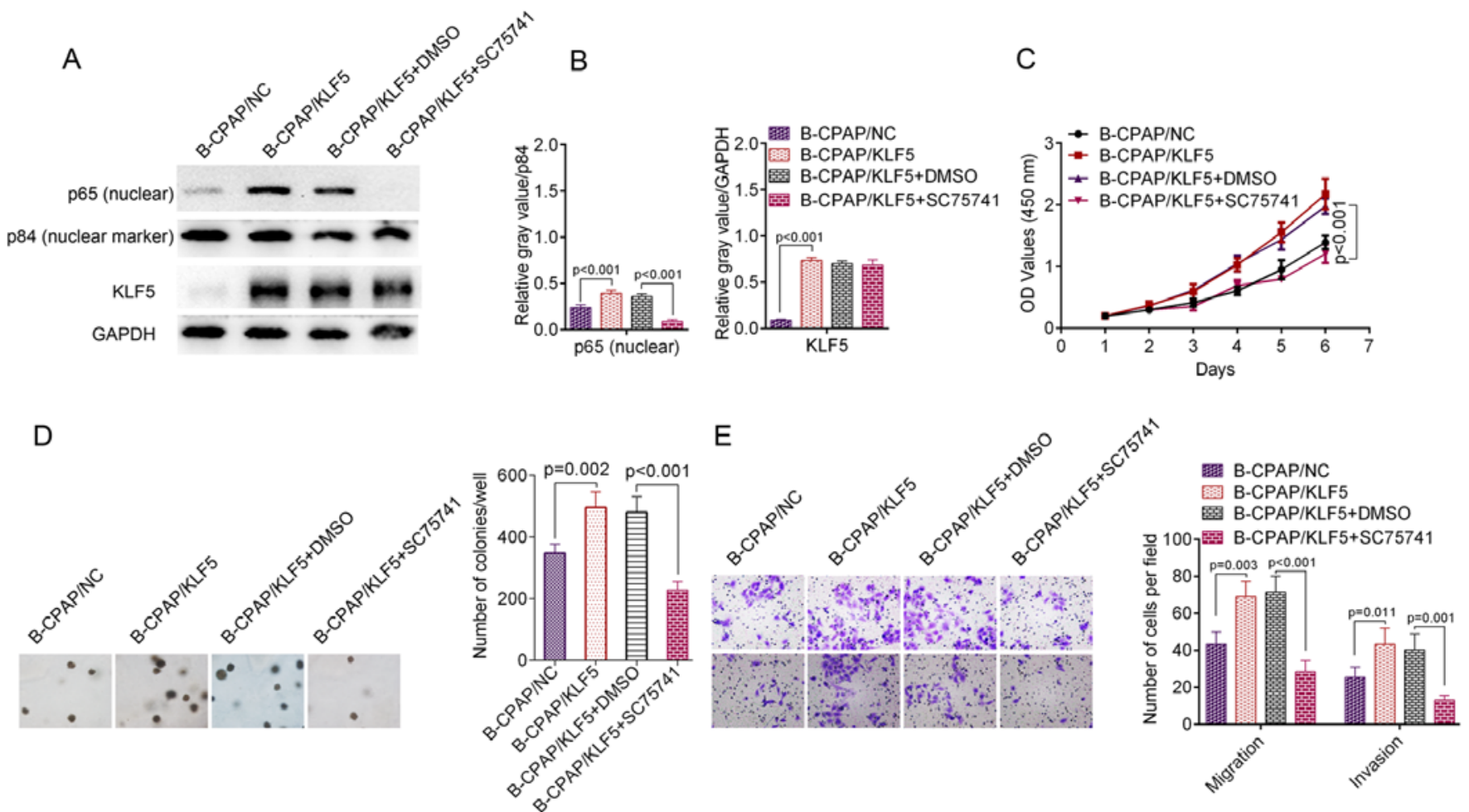

Figure 6. KLF5 promoted cell growth and metastasis through the NF- $\kappa$ B signalling pathway. B-CPAP/KLF5 cells were treated with the specific NF- $\mathrm{B}$ inhibitor SC75741 $(5 \mu \mathrm{M})$ and the effect was assessed. (A) B-CPAP/KLF5 cells were treated with SC75741 or DMSO for $48 \mathrm{~h}$. Western blotting of cell lysates from B-CPAP/NC, B-CPAP/KLF5, B-CPAP/KLF5+DMSO and B-CPAP/KLF5+SC75741 cells revealed that the NF-kB inhibitor SC75741 decreased the

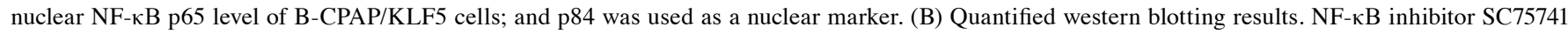
suppressed the (C) proliferation, (D) anchorage-independent growth and (E) migration/invasion ability of B-CPAP/KLF5 cells. NF- $\kappa B$, nuclear factor- $\kappa$ B; NC, negative control; KLF5, Kruppel-like factor 5; DMSO, dimethyl sulfoxide.

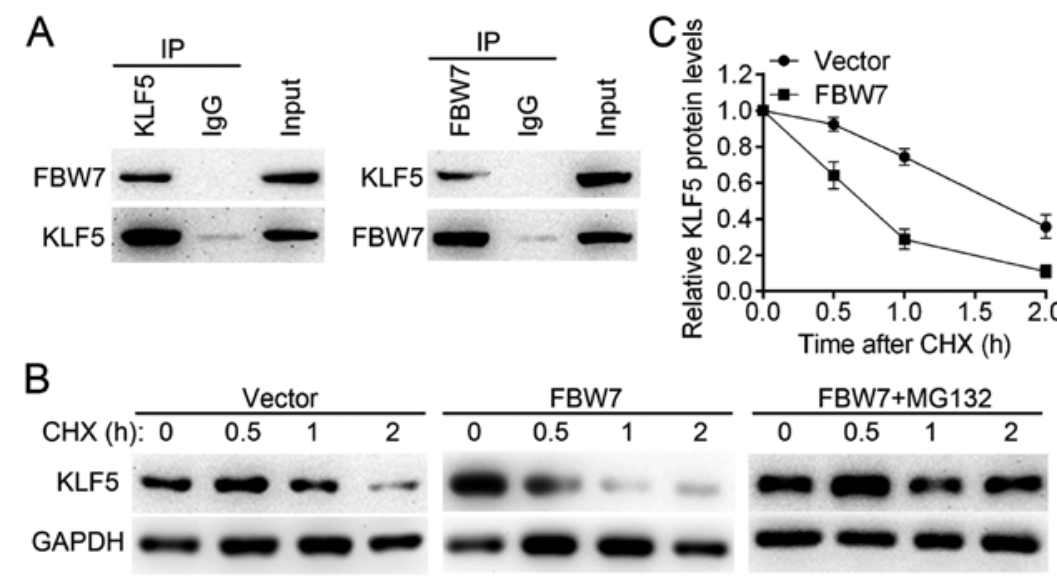

Figure 7. FBW7 promotes the proteasomal degradation of the KLF5 protein. (A) Interactions between KLF5 and FBW7 were assessed using a co-immunoprecipitation assay. Left panel: Cell lysates from SW579 cells were immunoprecipitated with anti-KLF5 or anti-IgG; right panel: Cell lysates from SW579 cells were immunoprecipitated with anti-FBW7 or anti-IgG. (B) Protein half-life of KLF5 was assessed following treatment with CHX (0.1 mg/ml). Additionally, MG132 treatment (5 $\mu \mathrm{M}$ for $8 \mathrm{~h}$ ) inhibited FBW7-induced KLF5 degradation in SW579 cells. (C) Quantified western blotting results. FBW7, F-box/WD repeat-containing protein 7; KLF5, Kruppel-like factor 5; IgG, immunoglobulin G; CHX, cycloheximide.

revealed that the FBW7-KLF5-NF-kB p65 axis is critical for the malignant phenotypes of thyroid cancer (Fig. 8C).

KLF5 promotes in vivo tumor growth and the metastasis of thyroid cancer cells. To investigate whether KLF5 was able to induce similar phenotypes in vivo, stable KLF5-silenced cells (SW579/shNC, SW579/shKLF5\#1 and SW579/shKLF5\#2) were established and the knockdown efficacy of KLF5 was verified by western blotting (Fig. 9A). A subcutaneous xenograft experiment in nude mice was then performed (Fig. 9B). The growth curves of the tumors revealed that the knockdown of KLF5 significantly inhibited SW579 cell growth in nude mice (shKLF5\#1, $\mathrm{P}<0.001$; shKLF5\#2, $\mathrm{P}<0.001$; Fig. 9C), and the tumor weight was significantly decreased in the SW579/ shKLF5\#1 or SW579/ shKLF5\#2 group compared with the SW579/shNC group (shKLF5\#1, $\mathrm{P}<0.001$; shKLF5\#2, $\mathrm{P}<0.001$; 
A

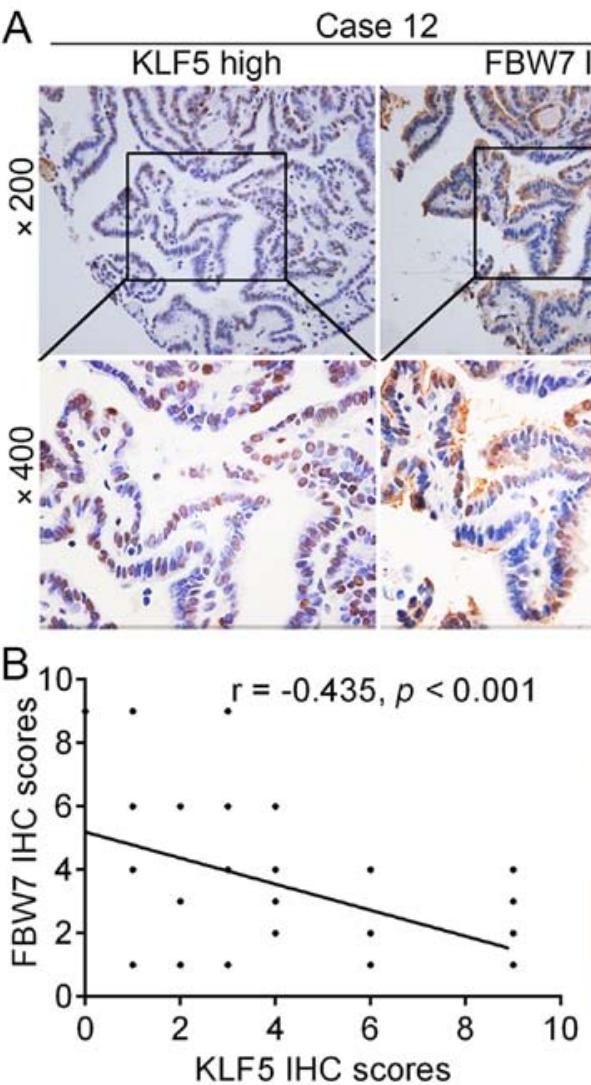

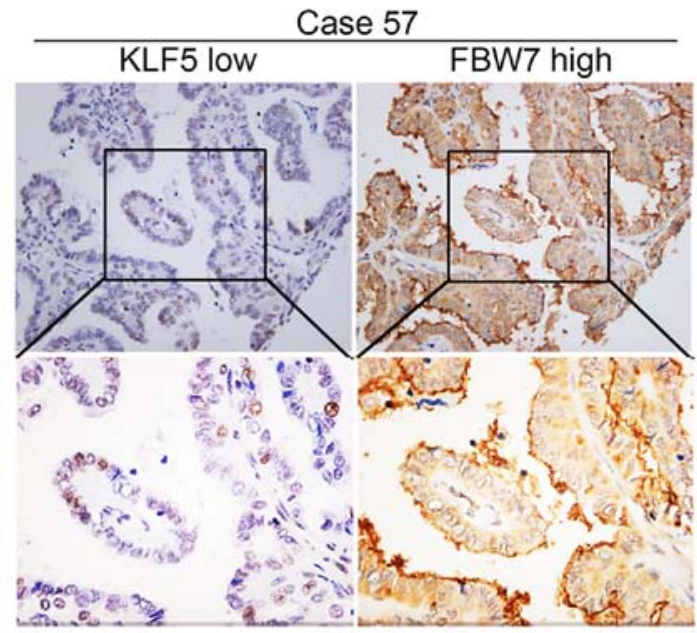

C

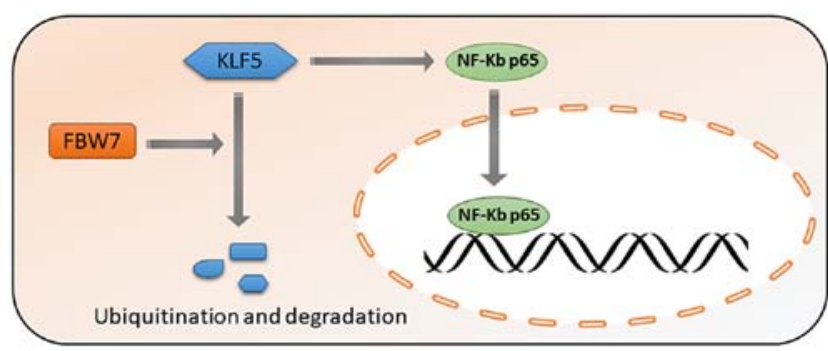

Figure 8. Correlation of KLF5 with the expression of FBW7 in the tissues of patients with thyroid cancer. (A) Representative IHC images of KLF5 and FBW7 in thyroid cancer tissues. (B) Correlation between the expression levels of KLF5 and FBW7 in thyroid cancer tissues. (C) Diagram presenting a summary of the results of the present study. It was proposed that the dysregulation of the tumor suppressor FBW7 reduces KLF5 degradation. Then, KLF5 promotes NF- $\mathrm{KB}$ p65 nuclear translocation, which in turn promotes the transcriptional levels of multiple downstream genes. FBW7, F-box/WD repeat-containing protein 7;

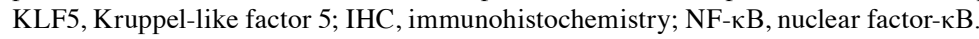

Fig. 9D). Subcutaneous tumor types derived from SW579/ shKLF5\#1 or SW579/shKLF5\#2 cells demonstrated increased levels of E-cadherin and decreased levels of KLF5 and ki67 compared with the SW579/shNC group (Fig. 9E). The results of the in vivo lung metastasis assay revealed that B-CPAP/KLF5 cells induced a significantly greater number of lung metastatic nodules in nude mice compared with B-CPAP/NC cells ( $\mathrm{P}=0.002$; Fig. 9F and $\mathrm{G}$ ), which suggested KLF5 is capable of manipulating the metastatic ability of B-CPAP cells in vivo.

\section{Discussion}

Extensive local invasion and distant metastasis are two major causes of recurrence and the mortality of patients with thyroid cancer (20), but the mechanisms of these processes remain elusive. In the present study, it was demonstrated that the protein expression of KLF5 was upregulated in thyroid cancer tissues compared with non-tumor tissues. Additionally, the overexpression of KLF5 was correlated with a higher tumor stage and lymph node metastasis. Thus, it is suspected that KLF5 may function as an oncogene in thyroid cancer.

The biological functions of KLF5 were evaluated in SW579 and B-CPAP cells. Previous studies have indicated that KLF5 has the potential to regulate cell proliferation (21), differentiation (22), metastasis (23) and stem cell characteristics (24). In the present study, KLF5 loss-of-function and gain-of-function assays were conducted to determine whether KLF5 was essential for the tumorigenesis of thyroid cancer cells. It was observed that the knockdown of KLF5 in SW579 cells significantly inhibited tumorigenesis in vitro and in vivo, while the overexpression of KLF5 in B-CPAP cells promoted tumorigenesis in vitro and metastasis in vivo. These results suggested that KLF5 may be critical for the unrestricted growth of thyroid cancer cells.

Another major characteristics of tumor cells is metastatic potential. In the present study, it was revealed that KLF5 promoted the migration/invasion ability of thyroid cancer cells. It was also observed that the knockdown of KLF5 decreased the protein levels of a number of pro-metastatic molecules, including fibronectin, vimentin and Twist1. However, the level of E-cadherin, which is generally considered as a metastatic suppressor accounting for cell adhesion, was upregulated following KLF5 knockdown. Furthermore, phalloidin staining (red) in SW579 cells expressing siKLF5\#1 and siKLF5\#2 revealed a significant reduction in actin stressfiber filaments, indicating weakened migratory and invasive capacity in these cells.

The aforementioned in vitro and in vivo phenotypes prompted further investigation into the mechanisms of KLF5 in thyroid cancer cells. The molecular pathogenesis of thyroid cancer involves multiple signalling pathways, including the PI3K/AKT (25), mitogen activated protein kinase/extracellular regulated kinase (26), Wnt/ $\beta$-catenin (27) and NF- $\kappa B$ pathways (28). A previous study indicated that lipopolysaccharide-induced oxidative stress upregulated KLF5 expression, 


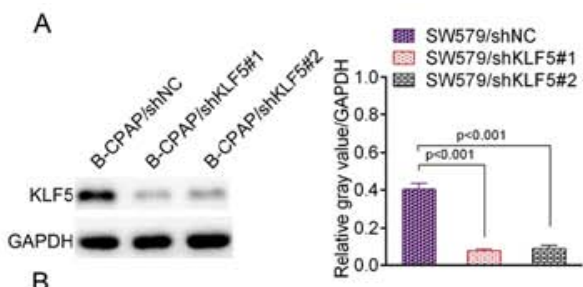

B-CPAP/shNC

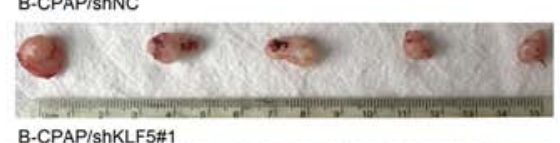

B-CPAP/ShKLF5\#1

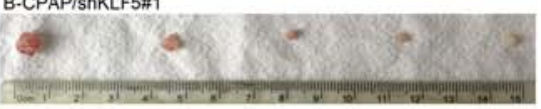

B-CPAP/ShKLF5\#2

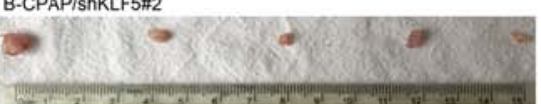

C
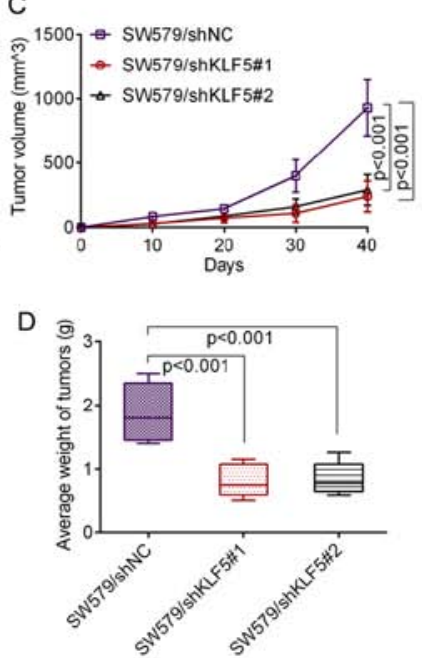

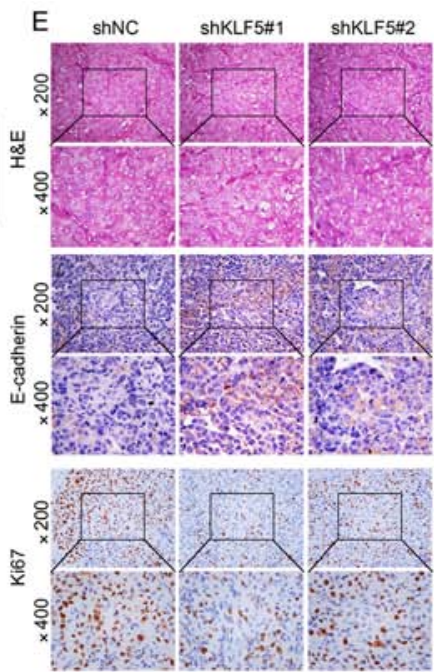

Figure 9. KLF5 promoted the in vivo tumor growth and metastasis of thyroid cancer cells. (A) Knockdown efficacy of KLF5 by two shRNAs was confirmed by western blotting. (B) SW579/shNC, SW579/shKLF5\#1 and SW579/shKLF5\#2 cells were subcutaneously injected into the right flanks of nude mice and (C) the growth curve of tumor volumes was obtained. (D) Mean weight of the tumors from the nude mice of the indicated groups. (E) Representative images of the immunohistochemistry analysis of KLF5, E-cadherin and ki67. (F) B-CPAP/NC and B-CPAP/KLF5 cells were injected intravenously into the tail vein of mice. Representative H\&E staining results of lungs are presented. (G) Number of lung metastatic foci in the B-CPAP/NC and B-CPAP/KLF5 groups (5 mice per group). KLF5, Kruppel-like factor 5; shRNA/sh, short hairpin RNA; NC, negative control; H\&E, hemotoxylin and eosin.

and thus promoted the phosphorylation and nuclear translocation of NF- $\kappa \mathrm{B}$ p65 (16). However, it remains unknown whether KLF5 is able to activate the NF- $\mathrm{B}$ signalling pathway in thyroid cancer cells. Regardless of the contribution from other mechanisms, the results of the present study provide strong evidence that the knockdown of KLF5 inhibited, while the overexpression of KLF5 promoted, the nuclear expression of $\mathrm{NF}-\kappa \mathrm{B}$ p65 in thyroid cancer cells. Inhibition of the NF- $\kappa \mathrm{B}$ pathway with a small molecule inhibitor blocked KLF5mediated phenotypes including cell growth and metastasis. These results associated KLF5 with an acknowledged signalling pathway, making KLF5 an attractive therapeutic target.

KLF5 expression may be regulated by different mechanisms at the mRNA level and protein level. Fu et al (21) revealed that DNA (cytosine-5)-methyltransferase 1-mediated promotor hypermethylation was responsible for the epigenetic silencing of KLF5 in clear cell renal cell carcinoma, which induced the frequent downregulation of KLF5 expression at the mRNA level. Thus, the present study evaluated the mRNA levels of KLF5 in 36 paired clinical samples. Unexpectedly, no significant difference in KLF5 mRNA expression was observed between thyroid cancer tissues and non-tumor tissues. By screening previously published literature, it was observed that the level of KLF5 may also be regulated through the ubiquitinproteasome system as KLF5 is a short-lived protein $(29,30)$. The most highly reported protein responsible for KLF5 degradation was E3 ubiquitin ligase FBW7. Zhao et al (19) reported that glycogen synthase kinase $3 \beta$ inducing the $S 303$ phosphorylation of KLF5 is essential for FBW7-mediated KLF5 degradation. In colon cancer cells, FBW7 interacted with KLF5 in a CDC4 phosphodegron-dependent manner and was responsible for KLF5-mediated cell proliferation (31). Of note, the IHC assay in the present study revealed that the protein levels of KLF5 in thyroid cancer tissues were significantly higher compared with non-tumor tissues, and were negatively correlated with FBW7 levels. Additionally, the exogenous expression of FBW7 in SW579 cells decreased the KLF5 protein half-life, which may be restored by the proteasome inhibitor MG132. These results revealed that the incontrollable expression of KLF5 was induced by the dysregulation of FBW7-mediated proteasomal degradation. This suggests a potential regulatory mechanism of KLF5 and requires further study.

In summary, the present study revealed that elevated expression of KLF5 in thyroid cancer tissues was correlated with lymph node metastasis. KLF5 promoted cell growth and metastasis of thyroid cancer cells through the NF- $\kappa \mathrm{B}$ signaling pathway. The present functional and mechanistic investigations suggest that targeting KLF5 may provide a potential therapeutic strategy for thyroid cancer.

\section{Acknowledgements}

Not applicable.

\section{Funding}

The present study was supported by the National Natural Science Foundation of China (grant no. 81570746 and 81770812 to GQ), the Innovation Scientists and Technicians Troop Construction Projects of Henan Province (grant no. 134200510021 to GQ) and the Young Foundation of the First Affiliated Hospital of Zhengzhou University (to LW).

\section{Availability of data and materials}

The datasets used and/or analyzed during the current study are available from the corresponding author on reasonable request.

\section{Authors' contributions}

YM and GQ planned the study. YM, QW and FL performed the experiments. YM, XM and LW performed the data analysis. 
FG, FH and SZ participated in the clinical sample collection. All authors read and approved the manuscript and agreed to be accountable for all aspects of the research in ensuring that the accuracy or integrity of any part of the work are appropriately investigated and resolved.

\section{Ethics approval and consent to participate}

The use of human tissue samples and experimental protocols were approved by the Medical Ethics Review Committee of Zhengzhou University (Zhengzhou, China), and written informed consent was obtained from each participant prior to enrolment in the study. All experiments were performed strictly in accordance with a protocol ethically approved by the Institutional Animal Care and Use Committee of Zhengzhou University.

\section{Patient consent for publication}

No identifying patient data were included in the present study.

\section{Competing interests}

The authors declare that they have no competing interests.

\section{References}

1. Jemal A, Bray F, Center MM, Ferlay J, Ward E and Forman D: Global cancer statistics. CA Cancer J Clin 61: 69-90, 2011.

2. La Vecchia C, Malvezzi M, Bosetti C, Garavello W, Bertuccio P, Levi F and Negri E: Thyroid cancer mortality and incidence: A global overview. Int J Cancer 136: 2187-2195, 2015.

3. Xing M: Molecular pathogenesis and mechanisms of thyroid cancer. Nat Rev Cancer 13: 184-199, 2013.

4. Hofstra RM, Landsvater RM, Ceccherini I, Stulp RP, Stelwagen T, Luo Y, Pasini B, Höppener JW, van Amstel HK, Romeo G, et al: A mutation in the RET proto-oncogene associated with multiple endocrine neoplasia type $2 \mathrm{~B}$ and sporadic medullary thyroid carcinoma. Nature 367: 375-376, 1994.

5. Russo D, Damante G, Puxeddu E, Durante C and Filetti S: Epigenetics of thyroid cancer and novel therapeutic targets. J Mol Endocrinol 46: R73-R81, 2011.

6. Sogawa K, Imataka H, Yamasaki Y, Kusume H, Abe H and FujiiKuriyama Y: cDNA cloning and transcriptional properties of a novel GC box-binding protein, BTEB2. Nucleic Acids Res 21: 1527-1532, 1993.

7. Dong JT, Boyd JC and Frierson HF Jr: Loss of heterozygosity at $13 \mathrm{q} 14$ and $13 \mathrm{q} 21$ in high grade, high stage prostate cancer. Prostate 49: 166-171, 2001.

8. Chen C, Brabham WW, Stultz BG, Frierson HF Jr, Barrett JC, Sawyers CL, Isaacs JT and Dong JT: Defining a common region of deletion at 13q21 in human cancers. Genes Chromosomes Cancer 31: 333-344, 2001.

9. Kojima S, Kobayashi A, Gotoh O, Ohkuma Y, Fujii-Kuriyama Y and Sogawa K: Transcriptional activation domain of human BTEB2, a GC box-binding factor. J Biochem 121: 389-396, 1997.

10. Dong JT and Chen C: Essential role of KLF5 transcription factor in cell proliferation and differentiation and its implications for human diseases. Cell Mol Life Sci 66: 2691-2706, 2009.

11. Du C, Gao Y, Xu S, Jia J, Huang Z, Fan J, Wang X, He D and Guo P: KLF5 promotes cell migration by up-regulating FYN in bladder cancer cells. FEBS Lett 590: 408-418, 2016.

12. Maehara O, Sato F, Natsuizaka M, Asano A, Kubota Y, Itoh J, Tsunematsu S, Terashita K, Tsukuda Y, Nakai M, et al: A pivotal role of Krüppel-like factor 5 in regulation of cancer stem-like cells in hepatocellular carcinoma. Cancer Biol Ther 16: 1453-1461, 2015
13. Ci X, Xing C, Zhang B, Zhang Z, Ni JJ, Zhou W and Dong JT: KLF5 inhibits angiogenesis in PTEN-deficient prostate cancer by attenuating AKT activation and subsequent HIF1 $\alpha$ accumulation. Mol Cancer 14: 91, 2015.

14. Saiselet M, Floor S, Tarabichi M, Dom G, Hébrant A, van Staveren WC and Maenhaut C: Thyroid cancer cell lines: An overview. Front Endocrinol (Lausanne) 3: 133, 2012.

15. Livak KJ and Schmittgen TD: Analysis of relative gene expression data using real-time quantitative PCR and the 2(-Delta Delta C(T)) Method. Methods 25: 402-408, 2001.

16. Chen HL, Chong IW, Lee YC, Tsai JR, Yuan SS, Wang HM, Liu WL and Liu PL: Krüppel-like factor 5 mediates proinflammatory cytokine expression in lipopolysaccharide-induced acute lung injury through upregulation of nuclear factor- $\kappa \mathrm{B}$ phosphorylation in vitro and in vivo. Mediators Inflamm 2014: 281984, 2014

17. Jing $\mathrm{H}$ and Lee $\mathrm{S}: \mathrm{NF}-\kappa \mathrm{B}$ in cellular senescence and cancer treatment. Mol Cells 37: 189-195, 2014.

18. Yang Y, Goldstein BG, Nakagawa H and Katz JP: Krüppel-like factor 5 activates MEK/ERK signaling via EGFR in primary squamous epithelial cells. FASEB J 21: 543-550, 2007.

19. Zhao D, Zheng HQ, Zhou Z and Chen C: The Fbw7 tumor suppressor targets KLF5 for ubiquitin-mediated degradation and suppresses breast cell proliferation. Cancer Res 70: 4728-4738, 2010.

20. Grebe SK and Hay ID: Thyroid cancer nodal metastases: Biologic significance and therapeutic considerations. Surg Oncol Clin N Am 5: 43-63, 1996.

21. Fu RJ, He W, Wang XB, Li L, Zhao HB, Liu XY, Pang Z, Chen GQ, Huang L and Zhao KW: DNMT1-maintained hypermethylation of Krüppel-like factor 5 involves in the progression of clear cell renal cell carcinoma. Cell Death Dis 8: e2952, 2017.

22. Oishi Y, Manabe I, Tobe K, Tsushima K, Shindo T, Fujiu K, Nishimura G, Maemura K, Yamauchi T, Kubota N, et al: Krüppel-like transcription factor KLF5 is a key regulator of adipocyte differentiation. Cell Metab 1: 27-39, 2005.

23. Jia L, Zhou Z, Liang H, Wu J, Shi P, Li F, Wang Z, Wang C, Chen W, Zhang H, et al: KLF5 promotes breast cancer proliferation, migration and invasion in part by upregulating the transcription of TNFAIP2. Oncogene 35: 2040-2051, 2016.

24. Parisi S, Passaro F, Aloia L, Manabe I, Nagai R, Pastore L and Russo T: Klf5 is involved in self-renewal of mouse embryonic stem cells. J Cell Sci 121: 2629-2634, 2008.

25. Qiu W, Xia X, Qiu Z, Guo M and Yang Z: RasGRP3 controls cell proliferation and migration in papillary thyroid cancer by regulating the Akt-MDM2 pathway. Gene 633: 35-41, 2017

26. Guan H, Guo Z, Liang W, Li H, Wei G, Xu L, Xiao H and Li Y: Trop2 enhances invasion of thyroid cancer by inducing MMP2 through ERK and JNK pathways. BMC Cancer 17: 486, 2017.

27. Xiang S, Xiang T, Xiao Q, Li Y, Shao B and Luo T: Zinc-finger protein 545 is inactivated due to promoter methylation and functions as a tumor suppressor through the Wnt/ $\beta$-catenin, $\mathrm{PI} 3 \mathrm{~K} / \mathrm{AKT}$ and MAPK/ERK signaling pathways in colorectal cancer. Int J Oncol 51: 801-811, 2017.

28. Lv N, Shan Z, Gao Y, Guan H, Fan C, Wang H and Teng W: Twist1 regulates the epithelial-mesenchymal transition via the $\mathrm{NF}-\kappa \mathrm{B}$ pathway in papillary thyroid carcinoma. Endocrine 51: 469-477, 2016.

29. Chen C, Sun X, Ran Q, Wilkinson KD, Murphy TJ, Simons JW and Dong JT: Ubiquitin-proteasome degradation of KLF5 transcription factor in cancer and untransformed epithelial cells. Oncogene 24: 3319-3327, 2005.

30. Zhi X, Zhao D, Zhou Z, Liu R and Chen C: YAP promotes breast cell proliferation and survival partially through stabilizing the KLF5 transcription factor. Am J Pathol 180: 2452-2461, 2012.

31. Liu N, Li H, Li S, Shen M, Xiao N, Chen Y, Wang Y, Wang W, Wang R, Wang Q, et al: The Fbw7/human CDC4 tumor suppressor targets proproliferative factor KLF5 for ubiquitination and degradation through multiple phosphodegron motifs. J Biol Chem 285: 18858-18867, 2010.

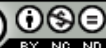

This work is licensed under a Creative Commons Attribution-NonCommercial-NoDerivatives 4.0 International (CC BY-NC-ND 4.0) License. 